\title{
Positive FDG PET/CT findings in a patient with pneumoconiosis
}

\author{
Tomohiro TAMURA ${ }^{1}$ \\ Gen OHARA ${ }^{1}$ \\ Katsunori KAGOHASHI ${ }^{1}$ \\ Hiroaki SATOH ${ }^{1}$
}

\footnotetext{
1 Division of Respiratory, Mito Medical Center, Tsukuba University, Mito, Japan

${ }^{1}$ Tsukuba Üniversitesi Mito Tıp Merkezi, Solunum Bölümü, Mito, Japonya
}

We previously read with interest the article by Yurdakul et al. on false positive 18F-FDG PET/CT findings mimicking malignant disease in patients with pneumoconiosis (1). We would like to share our experience.

A 78-year-old male presented with hemoptysis, dyspnea on effort, and generalized weakness. He had been a road workers for twenty-years. Chest X-Ray revealed hilar masses in both lungs. His pulmonary function test showed combined ventilatory impairment. Fluorine-18 fluoro-deoxy-glucose (18-F-FDG) positron emission tomography (PET) scan demonstrated significantly high metabolic pulmonary lesions with the delayed phase standardized uptake value of 11.5 (Figure 1). Sputum cytology showed no malignant cells. The patient refused further evaluation, therefore, transbronchial biopsy was not performed and followedup for five years. But the lesions were not changed.

Shukuya et al reported that cutoff level of SUVmax between patients with malignant lesion and pneumoconiosis was 5.0 (2). However, false positive 18F-FDG PET/CT findings mimicking malignant disease in some patients with pneumoconiosis $(1,3)$. Pneumocosis should be kept in mind for the differential diagnosis of cases that are positive in FDG-PET.

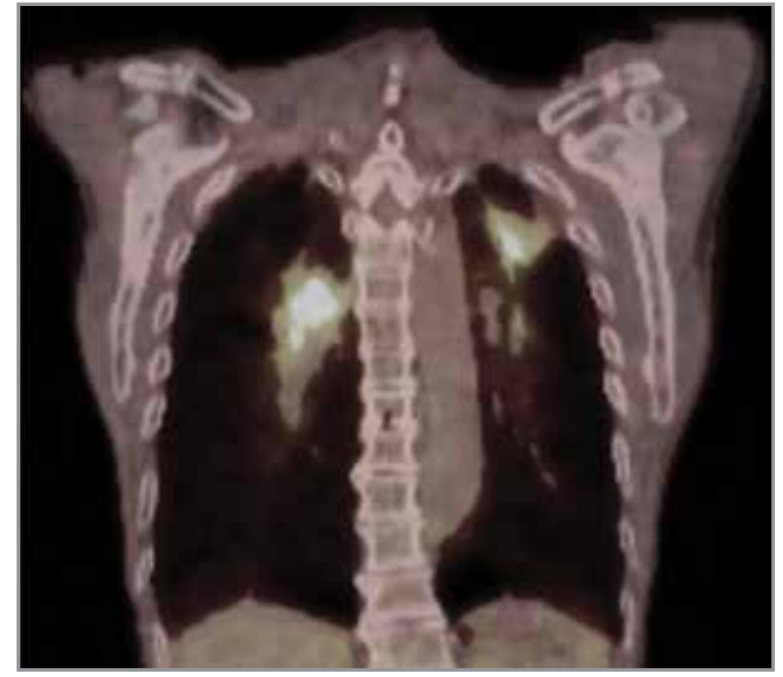

Figure 1. Fluorine-18 fluoro-deoxy-glucose positron emission tomography scan demonstrated significantly high metabolic pulmonary lesions with the delayed phase standardized uptake value of 11.5 .

\section{Yazışma Adresi (Address for Correspondence)}

Dr. Hiroaki SATOH

University of Tsukuba, Division of Respiratory Medicine, Mito Medical Center, MITO - JAPAN

e-mail: hirosato@md.tsukuba.ac.jp 


\section{REFERENCES}

1. Yurdakul AS, Varol A, Yeni Akten S, Öztürk C. False positive 18F-FDG PET/CT findings mimicking malignant disease in patients with pneumoconiosis. Tuberk Toraks 2012;60:269-73.

2. Shukuya T, Naka G, Kawana A, Sugiyama H, Kobayashi N, Kudo $K$, et al. Pneumoconiosis associated with an esophageal ulcer and uptake revealed in FDGPET. Intern Med 2006;45:293-6.
3. Yu $H$, Zhang $H$, Wang $Y$, Cui $X$, Han J. Detection of lung cancer in patients with pneumoconiosis by fluorodeoxyglucose-positron emission tomography/ computed tomography: four cases. Clin Imaging 2013;37:769-71. 